\title{
Correlation Between Personal, Structural, Intra-organizational Factors and Burnout in Teachers From Arab Schools in Israel
}

\author{
Osama Arar \\ West University of Timisoara, Timisoara, Romania
}

\begin{abstract}
The study aims at examining whether there was a correlation between school personal, structural, intra-organizational factors, general burnout level of teachers from Arab schools in Israel. The research question was: To what extent do personal, structural, and intra-organizational factors affect general burnout level of teachers? Quantitative data-collection was conducted through validated questionnaires from relevant scientific literature. Findings indicate a negative correlation between five styles of leadership and burnout, however, no significant correlation was found between all the personal variables and general burnout, with exception of the variables of years of teaching and age, that a positive significant correlation was found between these and burnout meaning that the higher years of teaching and age of teachers are, the higher burnout of same teacher is.
\end{abstract}

Keywords: burnout, intra-organizational factors, structural factors, leadership style

\section{Introduction}

A school is an interactive workplace in which there are multiple factors that affect a teacher's burnout. One of these factors is school structure. In current study the researcher would like to examine the extent of effect of school structure, personal variables, and intra-organizational variables, on burnout level of teachers from Arab schools in Israel, while addressing two intra-organizational variables: leadership style of school principal, management self-capability in teachers.

There are practically no studies in existence discussing the correlation among school structure, intra-organizational variables, and personal variables in teachers in general and in teachers in the Arab society in Israel in particular, and between burnout level of a teacher.

The purpose of current study is to examine the correlation among school structure, personal variables and intra-organizational variables, and between burnout level of teachers from Arab schools in Israel.

Schools are an important work environment for conducting of the study, as in light of an article by Arviv-Elyashiv and Zimmerman (2012), it became clear that in 2001, the percentage of teachers dropping out from the educational system reached $9.9 \%$ as opposed to $8.5 \%$ in 1991 . Meaning, an increase of $1.4 \%$ was noted in level of dropout of teachers from the system in with a decade.

Marom and Forbos (2006) indicate in their examination that percentage of teachers who drop out during the first working year or upon its completion is $24 \%$ in Primary education, $28 \%$ in High school, however, the highest percentage is that of teachers dropping out in first year amongst Junior-High school teachers (33\%).

Osama Arar, Ph.D. in management, West University of Timisoara, Timisoara, Romania.

Correspondence concerning this article should be addressed to Osama Arar, Jerusalem blvd 123 Tel-Aviv, Israel. 
Due to the fact that burnout has significant effect on level of functioning of a teacher in school, it is most important to know what causes burnout and how it is possible to moderate and reduce it and thus to improve the functioning of teachers and to improve the teaching-learning process. If we know what causes burnout, we will be able to lead to optimal functioning of principals and teachers in Israeli schools.

\section{Self-efficacy}

The term was borrowed from the field of personality psychology to organizational psychology, and this is how the term was attributed to the professional field of Man (Friedman, 2010). Professional self-efficacy is defined as beliefs of the professional in his ability to control events that affect his professional life (Kass, 2015).

A teacher's self-efficacy is defined as belief in the teacher's professional ability to affect his pupils' learning behavior and performance, to cause changes in their behavior and to control educational processes (Saracaloğlu \& Yenice, 2009).

On one hand, a teacher's capability for management is formed and shaped during his teaching career and the term includes the following components:

- Management capability which includes leadership capability.

- Human relations and managing foreign affairs of the school.

And on the other hand, capability for pedagogic management, meaning, teaching capability (Friedman, 2010).

Management styles to be examined in present article are the four management styles developed by Bolman and Deal (2008), and the additional pedagogical style by Cheng (1996) and Sergiovanni (2005). The author hopes that following the study it will be possible to indicate the recommended management style that can moderate burnout and by that improve functioning of teachers in school, their work and relation to the profession, the staff, the pupils, and the rest of those surrounding them.

\section{Burnout}

From reviewing of literature on the subject of burnout, it appears that the main reasons for burnout are connected to personal aspects, such as: sentimentality, idealism, dedication, and obsession on one hand and on the other hand to factors connected to the workplace, such as: big classes, lack of equipment and lack of help, few opportunities for promotion, lack of support from teachers and/or management, etc. (Simhon, 2000).

Research of teachers' burnout in Israel, began in Szold Institute in study year of 1984 and focused on burnout factors of a teacher in Primary education (Gonen, 2010). In recent years, mental burnout and pressure upon teachers became subjects of increasing public and professional interest. Burnout as a phenomenon, is discussed with relation to teachers and teaching more than any other professional field (Etzion, 1983; Shmerling, 2000).

Betoret (2006), studied the correlation between burnout and sense of self-efficacy and various pressure factors amongst Junior-High teachers in Spain. The findings of his study indicate that the higher self-efficacy level of a teacher and his power sources are, the less he would sense burnout.

Papastylianou, Kaila, and Polychronopoulos (2009) studied burnout of Primary school teachers in Greece. The findings of their study indicate that there is a correlation between teacher's burnout and other variables such as depression, duty ambiguousness, and role conflicts. However, they emphasize that comparing to other countries, in which the questionnaire for burnout measurement by Maslach and Jackson was used as well, teachers' burnout average in Primary schools in Greece is lower. 
Kinman, Wray, and Strange (2011), examined burnout amongst teachers in England. They examined the correlation between work overload, teacher's burnout and between satisfaction with work. The findings of their study support the correlation between work overload and burnout and between dissatisfaction from work. As a solution, they recommend to turn the teachers to training apprenticeships that would guide them in better coping with work overload. They also indicate the overt phenomena of a teacher's burnout are usually severe reactions of anger, anxiety, uneasiness, depression, tiredness, boredom, cynicism, sense of guilt, psychosomatic reactions, and in extreme cases mental breakdown as well.

\section{Research Question}

The study wishes to answer the following question:

To what do extent personal, structural, and intra-organizational factors affect the general burnout level of teachers?

\section{Research Hypotheses}

(1) A significant correlation will be found between personal variables and burnout level of a teacher.

(2) A significant correlation will be found between structural variables and burnout level of a teacher.

(3) A significant correlation will be found between intra-organizational variables and burnout level of a teacher.

\section{Methodology}

\section{Research Sample}

Three hundred thirty eight Arab teachers participated in the study. The sample selection represented the distribution of the Arab population in Israel.

\section{Research Tools}

The study is based on a closed questionnaire that includes scales which were examined and validated in previous studies. Following is a list of research variables:

$\underline{\text { Burnout }}$

$\underline{\text { Personal factors }}$

Gender (0-male; 1 -female)

Education (0-Bachelor Degree; 1—Master's Degree)

Age (in years)

Years of teaching seniority (in years)

Appointment percentage (in percentage)

$\underline{\text { Structural factors }}$

Ownership (0-public; 1 - private)

Number of teachers (1-15-29; 2-30-49; 3-50-79; 4-80 and above)

Number of pupils (1-150-299; 2-300-499; 3 - 500-799; 4-800 and above)

Intra-organizational factors

\section{Leadership Style}

A principal's leadership style is measured through a questionnaire that includes 40 items, which examine five leadership styles: structural-procedural, human resources approach, political, symbolic, and pedagogical 
(eight items for each leadership style) (Bolman \& Deal, 2008; Cheng, 1996). The teachers were asked to rate the principals' behavior on Likert scale with five grades (1-strongly disagree, 5-strongly agree). Internal reliability of the questionnaire is extremely high: structural procedural $(\alpha=0.949)$, human resources approach ( $\alpha=0.947)$, political $(\alpha=0.904)$, symbolic $(\alpha=0.953)$, and pedagogical $(\alpha=0.948)$.

\section{Self-efficacy}

Self-efficacy was measured through a questionnaire that was developed by Arar and Abramovitz (2013), which is comprised of 12 items. The teachers were asked to grade their answers on a five grades Likert scale ( 1 - strongly disagree, 5 - strongly agree). Internal consistency of the questionnaire is at stands 0.858 .

\section{Research Procedure}

The study was conducted in study year of 2015-2016, and data collection continued for about five months. After contacting with schools' principals with the purpose of receiving school entry authorization, we presented the subject of the study and its purposes and promised maintaining anonymity of responders and that the data will be used only for scientific purposes. The questionnaire was delivered in Arabic language by research assistants recruited for this purpose, its filling took about 30 minutes. It will be indicated that it was emphasized to the teachers that participation in the study is not mandatory. Due to that, before the questionnaires were distributed the teachers were asked to confirm their agreement to participate in the study.

\section{Findings Chapter}

\section{The Findings}

Table 1 presents the descriptive statistical data of the research variables: personal factors, structural factors, intra-organizational factors, and burnout. From Table 1 it is revealed that most of the study participants are female teachers $(77 \%)$. About two thirds of the participants $(67 \%)$ have Bachelor's degree. Average age of teachers is 38.37 , average of teaching years is 14.26 years, as opposed to average appointment percentage of 87.76. Additionally, Table 1 addresses the structural factors of a school. The table reveals that $92 \%$ of the teachers teach in public schools, about 55\% of them teach in schools employing between 30 to 49 teachers, and about $37 \%$ of them teach in schools in which study between 300 and 499 pupils. Regarding intra-organizational factors, the findings in Table 1 reveal that teachers report a high level of procedural leadership $(\mathrm{M}=3.95)$, human resources approach $(M=3.84)$, political $(M=3.75)$, symbolic $(M=3.90)$, pedagogical $(M=4.03)$, and self-efficacy $(M=3.87)$. Oppositely, teachers report a low level of burnout $(M=2.37)$.

Table 1

Averages (M), Standard Deviations (S.D.) and Percentages of Research Variables

\begin{tabular}{lll}
\hline Variable & $\mathrm{N}(\%)$ & $\mathrm{M}(\mathrm{S} . \mathrm{D})$. \\
\hline Personal factors & & \\
Gender & & \\
$\quad$ Male & $78(23.1)$ & --- \\
$\quad$ Female & $260(76.9)$ & --- \\
$\quad$ Education & & \\
$\quad$ Bachelor's degree & $226(66.9)$ & ---- \\
$\quad$ Master's degree & $112(33.3)$ & ---- \\
Age & ---- & $38.37(7.90)$ \\
Seniority & ---- & $14.26(8.03)$ \\
\hline
\end{tabular}


Table 1 continued

\begin{tabular}{lll}
\hline Variable & $\mathrm{N}(\%)$ & $\mathrm{M}(\mathrm{S} . \mathrm{D})$. \\
\hline Appointment percentage & ---- & \\
Structural factors & & \\
Ownership & & $-76(23.17)$ \\
$\quad$ Public & $311(92.0)$ & ---- \\
$\quad$ Private & $27(8.0)$ & \\
Number of teachers & & ---- \\
$\quad 15-29$ & $55(16.3)$ & ---- \\
$\quad 30-49$ & $185(54.7)$ & ---- \\
$\quad 50-79$ & $60(17.8)$ & ---- \\
$\quad 80$ and above & $38(11.1)$ & \\
Number of pupils & & ---- \\
$\quad 150-299$ & $51(15.1)$ & ---- \\
$\quad 300-499$ & $124(36.7)$ & ---- \\
$\quad 500-799$ & $122(36.1)$ & ---- \\
$\quad 800$ and above & $41(12.1)$ & \\
Intra-organizational factors & & $3.95(1.00)$ \\
Structural procedural & ---- & $3.84(1.05)$ \\
Human resources approach & ---- & $3.75(0.96)$ \\
Political & ---- & $3.90(1.07)$ \\
Symbolic & ---- & $4.03(1.00)$ \\
Pedagogical & ---- & $3.87(0.64)$ \\
Self-efficacy & ---- & $2.37(0.90)$ \\
Burnout & ---- & \\
\hline
\end{tabular}

Table 2 presents the variables correlations matrix: personal factors (gender, education, age, years of teaching, and appointment percentage), structural factors (ownership, number of teachers, and number of pupils), intra-organizational factors (procedural leadership, human resources approach leadership, political leadership, symbolic leadership, pedagogical leadership, and self-efficacy) and burnout. The table reveals that there is no statistically significant correlation between personal factors (gender, education, age, years of teaching, and appointment percentage) and burnout. Moreover, it was found that amongst structural factors (ownership, number of teachers, and number of pupils), only the variable of ownership has statistically significant correlation with burnout. Oppositely, statistically significant correlation was found between burnout and all variables of intra-organizational factors:

Structural procedural $(r=-0.65 ; p<0.001)$, human resources approach $(r=-0.67 ; p<0.001)$, symbolic $(r=-0.35 ; p<0.001)$, political $(r=-0.42 ; p<0.001)$, pedagogical $(r=-0.34 ; p<0.001)$, and self-efficacy $(r=-0.54$; $p<0.001)$.

For examination of effect of personal factors, structural factors and intra-organizational factor on burnout, a hierarchical multiple regression was performed (see Table 3). Model 1 included the personal factors: gender, education, age, years of teaching, and appointment percentage. Model 2 included in addition to personal factors, the structural factors: ownership, number of teachers, and number of pupils. Model 3 included in addition to personal and structural factors, the intra-organizational factors: procedural leadership, human resources approach leadership, political leadership, symbolic leadership, pedagogical leadership, and self-efficacy. 
Table 2

(Pearson's) Correlation Matrix of Research Variables

\begin{tabular}{|c|c|c|c|c|c|c|c|c|c|c|c|c|c|c|}
\hline & 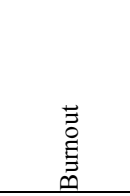 & 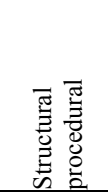 & 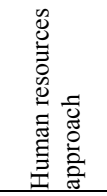 & 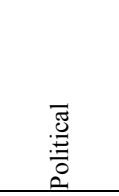 & 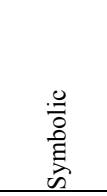 & 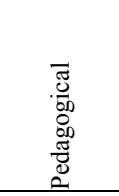 & 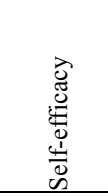 & $\begin{array}{l}\overrightarrow{\bar{v}} \\
\bar{\Xi} \\
0\end{array}$ & 总 & 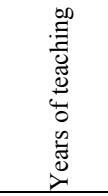 & 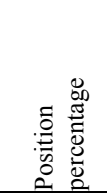 & 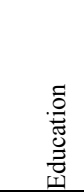 & 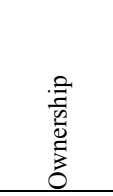 & 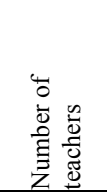 \\
\hline $\begin{array}{l}\text { Structural } \\
\text { procedural } \\
\text { Human } \\
\text { resources } \\
\text { approach }\end{array}$ & $\begin{array}{l}-0.65 * * * \\
-0.67 * * *\end{array}$ & $0.94 * * *$ & & & & & & & & & & & & \\
\hline Political & $-0.42 * * *$ & $0.93 * * *$ & $0.93 * * *$ & & & & & & & & & & & \\
\hline Symbolical & $-0.35^{* * *}$ & $0.96 * * *$ & $0.94 * * *$ & $0.94 * * *$ & & & & & & & & & & \\
\hline Pedagogical & $-0.34 * * *$ & $0.97 * * *$ & $0.94 * * *$ & $0.93 * * *$ & $0.96 * * *$ & & & & & & & & & \\
\hline Self-efficacy & $-0.54 * * *$ & $0.57 * * *$ & $0.65 * * *$ & $0.34 * * *$ & $0.37 * * *$ & $0.37 * * *$ & & & & & & & & \\
\hline Gender & 0.05 & -0.02 & 0.00 & 0.02 & 0.00 & 0.00 & $0.13^{*}$ & & & & & & & \\
\hline Age & 0.00 & 0.02 & 0.00 & 0.03 & 0.05 & 0.05 & 0.10 & $0.17 * *$ & & & & & & \\
\hline Seniority & 0.07 & -0.00 & -0.01 & -0.00 & 0.02 & 0.01 & 0.09 & $0.15^{* *}$ & $0.88^{* * *}$ & & & & & \\
\hline $\begin{array}{l}\text { Position } \\
\text { percentage }\end{array}$ & 0.08 & -0.07 & -0.07 & -0.06 & -0.06 & -0.04 & 0.01 & $0.14 *$ & $0.30 * * *$ & $0.35^{* * *}$ & & & & \\
\hline Education & -0.02 & -0.08 & -0.01 & -0.07 & -0.10 & -0.07 & 0.10 & 0.04 & $0.15^{* *}$ & $0.16^{* *}$ & $0.16^{* *}$ & & & \\
\hline Ownership & $0.12 *$ & $-0.13 *$ & -0.08 & $-0.12 *$ & $-0.12 *$ & $-0.14 * *$ & -0.09 & 0.04 & -0.08 & -0.10 & 0.01 & 0.05 & & \\
\hline $\begin{array}{l}\text { Number of } \\
\text { teachers }\end{array}$ & -0.04 & 0.05 & 0.04 & 0.08 & 0.07 & 0.07 & $-0.11 *$ & 0.05 & -0.05 & -0.10 & 0.01 & 0.10 & -0.05 & \\
\hline $\begin{array}{l}\text { Number of } \\
\text { pupils }\end{array}$ & -0.00 & 0.07 & 0.06 & 0.10 & 0.08 & 0.09 & -0.08 & 0.06 & -0.01 & -0.02 & 0.05 & 0.08 & $-0.19 * *$ & $0.73 * * *$ \\
\hline
\end{tabular}

Note. ${ }^{* * *} p<0.001 ;{ }^{* *} p<0.01 ;{ }^{*} p<0.05$.

From the first regression equation, a positive correlation appears among the variables of age and years of teaching and among burnout, the higher age and years of teaching of teachers are, the higher extent of burnout amongst them is. Additionally, it was found that there is no significant statistical correlation among the variables of gender, education, and appointment percentage and among burnout. Personal factors explained together $2.6 \%$ of the variance of burnout. In Model 2 it was found that old and senior teachers are yet with a higher level of burnout than young and not senior teacher. In addition, it was found that teachers who teach in privatized schools have a higher level of burnout than those who teach in public schools. And in conclusion, it was found that there is no statistically significant correlation between personality factors (gender, education, and appointment percentage) and structural factors (number of teachers and number of pupils) and between burnout. Personal and structural factors together managed to explain $4.4 \%$ of the variance of burnout.

The findings in Model 3 reveal that the positive correlations between burnout and variables of age and years of teaching have been retained, oppositely, correlation with the variable of ownership has vanished. Moreover, it was found that there is a negative correlation between burnout and between the intra-organizational factors: structural procedural and human resources leadership and self-efficacy, which means that the more teachers perceive leadership of a principal as structural procedural or as human resources, and hold a high sense of self-efficacy, thus the level of burnout amongst them reduces. In addition, no correlations were found between the intra-organizational factors: political leadership, symbolic leadership, pedagogical leadership, and between burnout. The personal factors, the structural factors, and the intra-organizational factors together managed to explain $30.8 \%$ of the variance of burnout.

Thus, it can be said that the intra-organizational factors are more important than personal factors and 
structural factors. This importance is seen clearly in the analysis of contribution of personal factors, structural factors, and intra-organizational factors. Personal factors managed to explain only $2.6 \%$ of the variance of the variable of burnout, while structural factors managed to explain only $1.8 \%$ and intra-organizational factors managed to explain $26.4 \%$.

Thus, the contribution of intra-organizational factors to explaining the variable of burnout is bigger than that of personal factors and structural factors.

Table 3

Hierarchical Multiple Regression for Prediction of Burnout by Personal Factors, Structural Factors, and Intra-organizational Factors

\begin{tabular}{llll}
\hline & Model 1 & Model 2 & Model 3 \\
\hline Personal factors & & & 0.09 \\
Gender (female-0) & 0.04 & 0.04 & $0.28^{* *}$ \\
Age & $2.16^{*}$ & $0.24^{*}$ & -0.02 \\
Education (Bachelor's degree-0) & -0.74 & -0.04 & $0.32^{* *}$ \\
Years of teaching & $2.25^{*}$ & $0.27^{*}$ & 0.00 \\
Appointment percentage & 1.14 & 0.05 & \\
Structural factors & & & 0.08 \\
Ownership (public-0) & & $0.13^{*}$ & -0.09 \\
Number of teachers & -0.08 & 0.08 \\
Number of pupils & 0.07 & $1.05^{* * *}$ \\
Intra-organizational factors & & & $0.95^{* * *}$ \\
Structural-procedural & & & 0.02 \\
Human resources approach & & & 0.06 \\
Political & & & -0.15 \\
Symbolic & & & $-1.08^{* * *}$ \\
Pedagogical & & $\mathbf{0 . 3 0 8}$ \\
Self-efficacy & $\mathbf{0 . 0 4 4}$ & \\
$\mathrm{R}^{2}$ & $\mathbf{0 . 0 2 6}$ & & \\
\hline
\end{tabular}

Note. ${ }^{* * *} p<0.001 ; * * p<0.01 ; * p<0.05$.

\section{Discussion and Conclusions}

The first research hypothesis was that correlation will be found between personal variables and between level of burnout of a teacher in his school. The hypothesis was partially confirmed and no significant correlation was found between all the personal variables and between general burnout, with exception of the variables of years of teaching and age, that a positive significant correlation was found between these and burnout. Meaning that the higher years of teaching and age of teachers are, the higher burnout of same teacher is. The hypothesis regarding a correlation between structural variables and level of burnout of teachers was not confirmed as well, with the exception of the variable of ownership, thus it was found that the level of burnout of teachers who teach in schools of private ownership is higher than that of teachers who teach in public schools, this stemming apparently from a feeling of employment security in schools owned by the State, not to mention that these teachers receive tenure after two years of work.

Another possible cause for a rise in rate of burnout in teachers who teach in private schools is high and numerous requirements of teachers who teach there, as these schools are in a constant competition with public schools and are interested in routing into them pupils whose parents pay for them a high tuition fee. A principal 
invests in contacts with external factors for the purpose of enhancing effectiveness in school managing and establishing status and prestige of the school (Friedman, 1993).

The third hypothesis was partially confirmed, thus, a significant correlation was found between most of the intra-organizational variables and between the level of burnout of a teacher. A significant negative correlation was found between structural-procedural leadership style and human resources approach and between the level of burnout of a teacher, thus, the more teachers perceive a principal's leadership as structural-procedural or as human resources, they hold a high sense of self-efficacy and thus the level of burnout amongst them reduces.

One of the reasons for the fact that human resources leadership style mitigates the sense of burnout, is that this feeling is brought about when a teacher senses that the efforts he invests do not bear fruit and his actions are not useful. The human resources leadership style emphasizes needs of a person, adjusts the organization to people as well as their significance. When a principal supports a teacher, strengthens him, takes care of his motivation, and emphasizes inter-personal relations, the sense of nonfulfillment reduces.

The hypothesis regarding self-efficacy was found to be confirmed in relation to burnout. Meaning, the higher the level of self-efficacy for management in a teacher is, the more his level of burnout will be reduced.

Practical recommendations: the research findings indicate a contribution of leadership style to level of burnout and self-efficacy of teachers in a school. Thus, if there is an intent of mitigating the level of burnout of teachers, and enhancing their level of self-efficacy, the style of a school principal may indeed assist in it.

\section{References}

Arviv-Elyashiv, R., \& Zimmerman, V. (2012). Dropout from teaching in Israel: Motives, risk factors and coping from the perspective of the educational system. Research Paths, 18, 52-62.

Arar, K., \& Abramovitz, R. (2013). Teachers' attitudes toward the appointment of women as school leaders: The case of the Arab education in Israel. Management in Education, 27(1), 29-35.

Betoret, D. F. (2006). Stressors, self-efficacy, coping resources, and burnout among secondary school teachers in Spain. Educational Psychology, 26(4), 519-539.

Bolman, L. G., \& Deal, T. E. (2008). Reframing organizations: Artistry, choice, and leadership (4th ed.). San Francisco, CA: Jossey-Bass.

Cheng, Y. C. (1996). School effectiveness and school-based management: A mechanism for development (Vol. 1). Psychology Press.

Etzion, D. (1983). Personal erosion-Theory and research at the crossroads. Tel-Aviv: Tel-Aviv University, the Faculty of Management.

Friedman, Y., \& Berma, R. (2010). Self-efficacy of school principal: the term and its components. Reviews in Organization and Administration of Education. Haifa: Haifa University, pp. 57-94.

Friedman, Y., \& Lotan, A. (1993). Pressure and burnout in teaching-Causes and ways of prevention. Henrietta Szold Institute.

Gonen, T. (2012). What is between management style, academic understanding and school achievements level? Working Paper for Master's degree in Education, Policy and Administration of Education, Tel-Aviv University.

Kass, E. (2015). I was always the good girl: The twofold silencing of teachers as a force fostering a low sense of professional self-efficacy. Gender and Education, 27(5), 487-504.

Kinman, G., Wray, S., \& Strange, C. (2011). Emotional labour, burnout and job satisfaction in UK teachers: The role of workplace social support. Educational Psychology, 31(7), 843-856.

Marom, A., \& Forbos, Y. (2006). New teachers dropout from the education system. Central Bureau of Statistics.

Oplatka, Y. (2002). Burnout and innovation—Life story of school principals in Israel. Book Publication of Ben-Gurion University of the Negev.

Oplatka, Y. (2012). School management from appointment to the retirement. Pardes Publication.

Papastyilanou, A., Kaila, M., \& Polychronpoulos, M. (2009). Teachers' burnout, depression, role ambiguity and conflict. Social 
Psychology of Education, 12(3), 295-314.

Saracaloğlu, A. S., \& Yenice, N. (2009). Investigating the self-efficacy beliefs of science and elementary teachers with respect to some variables. Journal of Theory and Practice in Education, 5(2), 244-260.

Sergiovanni, T. J. (2005, June). The virtues of leadership. In The Educational Forum 69(2), 112-123. Taylor \& Francis Group. Shmerling, H. (2000). Mental erosion of teachers: “dewy lights”, chapter 9. Elkana: Orot College Israel, pp. 336-378.

Simhon, A. (2000). Variables that predict middle school teachers burnout in Israel. Reading and Studying: Journal of Teaching of Humanities and Social Sciences, 78, 17-23. 